Archived version from NCDOCKS Institutional Repository http://libres.uncg.edu/ir/asu/

\title{
Appalachǐan
}

B O O N E, N O R T H C A R O L I N A

\section{Predicting Paternalism: Welfare Asset Limits And State-Level Demographic, Economic, And Political Factors}

\author{
By: Leah Hamilton, Peter R. Fawson, and Taylor Dollar
}

\begin{abstract}
Welfare eligibility is usually determined via income and financial assets. Since devolution of Temporary Assistance for Needy Families administration in 1996, there is significant state variation in these criteria. Previous research suggests that income limits are influenced by racial politics, with more restrictive criteria associated with higher Black populations. The current study examined whether asset testing is similarly determined. Findings indicate that asset tests are positively associated with a democratic State Senate, median income, and the percentage of Black residents. The presence of advocates seeking to advance asset-building opportunities to low-income families may have influenced this divergence in income and asset testing.
\end{abstract}

Leah Hamilton, Peter R. Fawson \& Taylor Dollar (2019): Predicting Paternalism: Welfare Asset Limits and State-Level Demographic, Economic, and Political Factors, Journal of Poverty, DOI: 10.1080/10875549.2019.1587658. Publisher version of record available at: https://www.tandfonline.com/doi/full/10.1080/10875549.2019.1587658 


\title{
Predicting Paternalism: Welfare Asset Limits and State-Level Demographic, Economic, and Political Factors
}

\author{
Leah Hamilton (D), Peter R. Fawson (D), and Taylor Dollar \\ Department of Social Work, Appalachian State University, Boone, NC, USA
}

\begin{abstract}
Welfare eligibility is usually determined via income and financial assets. Since devolution of Temporary Assistance for Needy Families administration in 1996, there is significant state variation in these criteria. Previous research suggests that income limits are influenced by racial politics, with more restrictive criteria associated with higher Black populations. The current study examined whether asset testing is similarly determined. Findings indicate that asset tests are positively associated with a democratic State Senate, median income, and the percentage of Black residents. The presence of advocates seeking to advance asset-building opportunities to low-income families may have influenced this divergence in income and asset testing.
\end{abstract}

\section{KEYWORDS}

Families in poverty; welfare reform; race

The Personal Responsibility and Work Opportunity Reconciliation Act (PRWORA) of 1996 devolved determination of maximum participant assets to states in the newly created Temporary Assistance for Needy Families (TANF) program. Today, many asset limits remain at 1980s' levels whereas others have been significantly increased or eliminated altogether. Liberalized limits are associated with increased savings and vehicle ownership among low-income families and decreased administrative costs. According to advocates, this change provides low-income families with an important opportunity to gain financial independence (Prosperity Now, 2018). However, no previous research has examined the factors affecting state-level decision making regarding asset limits. The eight states to eliminate limits altogether (Alabama, Colorado, Hawaii, Illinois, Louisiana, Maryland, Ohio, and Virginia) appear at first glance to represent a diversity of political and economic conditions. The study described here therefore tests the relationship between TANF asset limits and various state-level demographic, economic, and political factors via

CONTACT Leah Hamilton hamiltonl@appstate.edu

Authors Note

An earlier version of this paper was presented at the Society for Social Work and Research conference in January, 2018. 
the creation of panel data set for all 50 states and the District of Columbia for the years 1999 to 2015 .

\section{Literature review}

Welfare asset limits were first set at $\$ 1,000$ by Reagan's Omnibus Budget Reconciliation Act of 1981 (McDonald, Orszag, \& Russell, 2005). Since passage of PRWORA in 1996, policy think tanks such as Prosperity Now (2018) and the Urban Institute have advocated for state liberalization of the asset test remove barriers to asset building for low-income families. This work is situated within a broader framework of asset-development efforts to combat poverty and stagnant economic mobility. Asset-development efforts such as Individual Development Accounts (IDAs) and Child Savings Accounts have been found to improve not only family financial stability, but also mental well-being and future planning (Bent-Goodley et al., 2016). Low asset limits in public assistance programs, however, mean that families in need of assistance are essentially blocked from asset-building efforts. Although 30 states now exclude IDAs from asset testing for TANF and 14 states exclude 529 college savings accounts, more common assets such as savings accounts and vehicles continue to face scrutiny (Prosperity Now, 2018).

Today, asset limits vary significantly and range from $\$ 1,000$ to $\$ 10,000$; however, the threshold for the majority of states is at or below $\$ 2,500$ (Pew Charitable Trusts, 2016). Overall, 37 states impose asset limits at or below $\$ 3,000$ (Gehr, 2016). The $\$ 1,000$ limit remains in effect for several states: Georgia, Indiana, Washington, New Hampshire, Missouri, Oklahoma, Pennsylvania, Rhode Island, and Texas (Gehr, 2016). Some of the states with $\$ 1,000$ limits for applicants increase the limit for recipients, which should theoretically allow for asset building once enrolled in the program (Gehr, 2016). For example, the applicant limit for Missouri is $\$ 1,000$, whereas recipients can accumulate assets up to $\$ 5,000$ without sanction (Gehr, 2016). New Hampshire and Indiana also allow recipients to have more assets than applicants, but the amounts are somewhat negligible. For instance, Indiana recipients can increase assets to $\$ 1,500$ and New Hampshire recipients can increase assets to $\$ 2,000$ (Gehr, 2016). Oregon increases the asset limits for recipients to $\$ 10,000$ from $\$ 2,500$ for applicants (Gehr, 2016). Conversely, Minnesota (passed in 2016) and Delaware have the most liberalized asset limits: $\$ 10,000$ for applicants and recipients (Gehr, 2016).

The elimination or liberalization of TANF asset limits increases administrative savings in multiple states and contexts. After Virginia eliminated asset limits, the state saved an estimated $\$ 300,000$ in administrative costs annually because caseworkers were no longer verifying assets (Corporation for Enterprise Development, 2013). Overall, states that eliminate or raise asset limits to at least $\$ 3,000$ report an estimated $2 \%$ administrative savings per year (Pew Charitable 
Trusts, 2016). Between 2013 and 2014, California spent nearly $\$ 6.4$ million on the asset-testing process, only to discover minimal violations (Brown-Robertson \& Otabor, 2015). Only $2 \%$ of applicants were found to be ineligible for the program due to cash assets during that time (Brown-Robertson \& Otabor, 2015). Aside from explicitly monetary savings, an argument can be made for a savings of resources and time. For example, removal of asset testing can lead to faster service delivery due to a decrease in time related to filling out the application and verifying assets (Gehr, 2016).

Despite administrative savings successes, other concerns may cloud the perception of asset-limit elimination. Changes to a state caseload, for example, is commonly employed to measure the success or failure of welfare reform (Schram \& Soss, 2001). Thus, an increase in caseload size is a common concern regarding the elimination or liberalization of resource limits. Despite this worry, Virginia and Ohio did not experience caseload increases after TANF asset limits were eliminated (Rand, 2007). An additional analysis indicates no caseload increases for five states that eliminated or liberalized, even though the analysis was conducted during the Great Recession and soaring unemployment rates (Hamilton, Alexander-Eitzman, \& Royal, 2015). Between the years of 2000 and 2014, TANF caseloads experienced a general decrease (roughly 38\%) as an overarching trend (Pew Charitable Trusts, 2016). Only six states experienced increases in caseloads during this time, and just one of those states had eliminated asset limits (Pew Charitable Trusts, 2016). Louisiana and Ohio, two states with eliminated asset tests, experienced decreases greater than or equal to $50 \%$ during this period (Pew Charitable Trusts, 2016). If caseload size is associated with the perceived success of TANF or other welfare reforms, the elimination or liberalization of asset testing should therefore be considered a successful reform to the existing policy.

Aside from caseload implications, asset-limit elimination may also affect recipients' savings behaviors. One study suggests that TANF asset-limit liberalization is associated with an overall increase in all low-income families' savings as opposed to just welfare recipients (Nam, 2008). An important factor from the study is time: the longer a liberalized asset limit has been in effect, the more likely a population will save or open bank accounts (Nam, 2008). Other research yields mixed results regarding savings behavior. For example, a study of female-headed households between 1978 and 1983 indicated a $\$ 0.25$ decrease in savings per $\$ 1$ assetlimit decrease (Powers, 1998). Conversely, another study of a similar population between 1994 and 2001 indicated no association regarding savings rates and asset limits; however, the findings did suggest that vehicle restrictions may have an impact on female-headed household car purchase and ownership (Hurst \& Ziliak, 2006). Sullivan (2006) similarly determined "full vehicle exemption increases average vehicle equity by about \$565” (p. 103). 
Vehicle ownership is particularly important when considering employment opportunities (Bansak, Mattson, \& Rice, 2010). For example, having a vehicle can help employees or future employees attend job interviews, go to work, and maintain employment without missing days due to a lack of transportation. Qualitative research also suggests potential links between getting hired and owning a vehicle (Fletcher, Garasky, Jensen, \& Nielsen, 2010). Rural areas can be troublesome in particular. For instance, commuting jobs often yield more income; however, reliable transportation is necessary for such employment opportunities and public transit may not be an option (Fletcher et al., 2010). Participants in Fletcher et al. (2010) study were asked about reliable transportation and car ownership during job interviews. Some of the participants had social support networks allowing for vehicle exchange but still found the lack of individual vehicle ownership to be problematic for situations like working third shift (Fletcher et al., 2010). Another study indicated a relationship between vehicle ownership and employment in urban areas as well. Overall, having a vehicle helps facilitate employment in sprawling cities (Ong, 2002). Ong's (2002) analysis suggests that vehicle ownership increases the chances of employment by 9\%. Currently, 19 states exempt all household vehicles from the asset-testing process (Gehr, 2016).

Presently, eight states have eliminated asset limits in general. Ohio was the first state to eliminate in 1997, followed by Virginia in 2003. Alabama, Louisiana, Maryland, Hawaii, Illinois, and Colorado all eliminated resource testing as an eligibility criterion between 2009 and 2014. Colorado initially liberalized the limit to $\$ 15,000$ in 2006 before eliminating it completely in 2011 (Corporation for Enterprise Development, n.d.; Hamilton et al., 2015). All of these states, aside from Virginia, have also eliminated asset testing for the Supplemental Nutrition Assistance Program (SNAP) (Gehr, 2016).

\section{How are TANF asset limits determined?}

It is not yet clear how and why states set TANF asset-limits policies. Previous research has explored the ways in which economics, politics, institutional structures, and racial disparities affect welfare policy (Amenta, Bonastia, \& Caren, 2001; Piven \& Cloward, 1993; Soss, Fording, \& Schram, 2008). Some research suggests that the various safety net programs are affected by differing factors. In other words, the logic behind retrenchment may vary by program. The Children's Health Insurance Program (CHIP), for example, tends to reflect the condition of the state economy. Specifically, states with a higher poverty rate actually set higher income thresholds for CHIP eligibility (Brown \& Best, 2017). Conversely, SNAP policy reflects political and institutional dynamics, with Republican governors presiding over significantly more restrictive eligibility policies (Brown \& Best, 2017). 
In the case of TANF, shifts toward local welfare control, or devolution, have enabled policy inequities in terms of regulations, funding, and service delivery in areas with large populations of people of color (Soss et al., 2008). Racist perceptions of low-income families have been consistently linked to paternalistic and punitive TANF policy (Brown \& Best, 2017; Soss et al., 2008). Further, TANF policy choices are less likely to be affected by the ratio of Asian and White Americans when compared to ratios of African to White Americans (Soss et al., 2008). In Brown and Best's (2017) analysis, political dynamics appeared to have a minimal effect on TANF policy generosity. Although Republican administrations tend to publicly denounce cash benefit programs, blue states do not typically reflect a systemic generosity in eligibility requirements either (Brown \& Best, 2017).

However, to quantify TANF generosity, previous researchers have examined total program expenditures, the degree of local devolution, and the income threshold for eligibility (Brown \& Best, 2017; Soss et al., 2008). No previous research has considered whether TANF asset limits are similarly determined. In the following analysis, we seek to determine the predictive relationships between state TANF asset limits, racial demographics, politics, and economic conditions as each of these factors can arguably influence welfare generosity. We also controlled for maximum monthly TANF benefits, attempting to rule out the possibility that asset limits are simply a proxy measure for other generous policies.

\section{Methods}

To determine the factors predicting state-level asset-limit determination, we created a balanced panel for 50 states and District of Columbia over the fiscal years 1999-2015 as no single public database contains all of the necessary variables to properly address the research question. Previous TANF research (Brown \& Best, 2017; Soss et al., 2008) suggests that asset-limit determination will be influenced by state economic trends, politics, and racial demographics. We therefore collected asset limits and maximum monthly TANF benefit via the Urban Institute's Welfare Rules Database (2018), unemployment rates via the Bureau of Labor Statistics (2018), poverty rates via the US Census (2018a), and State House and Senate makeup via the University of Kentucky's Center for Poverty (2017) welfare data set. State race and income demographics were collected via the American Community Survey (ACS) (US Census Bureau, 2018b) for the years 2005-2015 (the ACS is only available from 2005 on the US Census website). Data was organized by state and year for a total of 867 state-year data points.

All independent variables (poverty rate, unemployment rate, percentage of state upper and lower house that is Democratic, maximum TANF benefit, median income, and state race distribution) were continuous. The dependent 
variable, state asset limits for current recipients (which can sometimes differ from those for applicants), was converted to a categorical variable to account for states that had eliminated the limit entirely $(1=0-999,2=1,000-1999$, $3=2000-2999,4=3000-3999,5=4000-4999,6=5000-5999$, $7=6000-6999,8=7000-7999,9=8000-8999,10-9000-9999,11=10,000+$, 12 = no limit). Financial data, including median income and maximum monthly benefit was reported in constant dollars and not adjusted for inflation. We first explored the data via a bivariate analysis, utilizing a Pearson's correlation. We then completed a multiple regression with all variables. The statistical software Statistical Package for the Social Sciences (SPSS) 24.0 was used for all statistical analysis.

\section{Findings}

\section{Descriptive statistics}

Several states changed or eliminated their asset test during the examination period. Table 1 provides each state's limits for the period 1999-2015. In some states, there are multiple limits based upon household composition. For simplicity, this analysis examines the lowest limit within a state.

Table 1. State Asset Limits (1999-2015)

\begin{tabular}{ll}
\hline Variable & \multicolumn{1}{c}{ Static Limits } \\
\hline GA, OK, PA, RI, WA & $\$ 1,000$ \\
IN & $\$ 1,500$ \\
AK, AZ, DC, FL, KY, ME, MS, & $\$ 2,000$ \\
NH, NJ, NY, SD, TN, UT, WV & \\
MA, SC, WI, WY & $\$ 2,500$ \\
AR, CT, MI, MT, NC & $\$ 3,000$ \\
NM & $\$ 3,500$ \\
NE & $\$ 4,000$ \\
IA, MN, MO & $\$ 5,000$ \\
OR & $\$ 10,000$ \\
Variable & Eliminated limits \\
OH & No limits \\
VA & $\$ 1,000(99-03)$, No limit $(04-15)$ \\
AL, MD & $\$ 2,000(99-09)$, No limit $(10-15)$ \\
LA & $\$ 2,000(99-10)$, No limit $(11-15)$ \\
IL & $\$ 2,000(99-13)$, No limit $(14-15)$ \\
CO & $\$ 2,000(99-06), \$ 15,00(07-10)$, No limit $(1-15)$ \\
HI & $\$ 5,000(99-12)$, No limit $(13-15)$ \\
Variable & Increased limits \\
AK & $\$ 1,000(99-01), \$ 2,000(02-15)$ \\
VT & $\$ 1,000(99-07), \$ 2,000(08-15)$ \\
DE & $\$ 1,000(99-09), \$ 10,000(10-15)$ \\
CA, KS & $\$ 2,000(99-14), \$ 2,250(15)$ \\
ID & $\$ 2,000(99-11), \$ 5,000(12-15)$ \\
NV & $\$ 2,000(99-13), \$ 6,000(14-15)$ \\
Variable & Decreased limits \\
TX & $\$ 2,000(99-03), \$ 1,000(04-15)$ \\
ND & $\$ 5,000(99-00), \$ 3,000(01-15)$ \\
\hline
\end{tabular}


For all state-years (1999-2015), states experienced a mean unemployment rate of $5.776 \%(S D=2.003)$, a mean poverty rate of $12.684 \%(S D=3.475)$, and a mean median income of $\$ 51,221.955(S D=8848.725)$. State mean TANF maximum monthly benefits for a family of three were $\$ 425.269$ $(S D=161.512)$. Regarding state legislative makeup, states reported a mean Democratic composition of 50.8\% $(S D=16.2)$ in the House and $49.8 \%$ $(S D=17.4)$ in the Senate. Finally, state racial makeup included a mean of $77.3 \%$ White $(S D=13.7), 11.1 \%$ Black $(S D=11.0), 1.6 \%$ American Indian or Alaska Native $(S D=2.8), 3.7 \%$ Asian $(S D=5.5), 0.3 \%$ Native Hawaiian or Pacific Islander $(S D=1.3), 3.2 \%$ "Some other race," $(S D=3.1)$, and $2.9 \%$ multiracial $(S D=3.1)$. All descriptive statistics for independent variables are presented in Table 2.

\section{Correlations}

In our bivariate analysis, asset limits were significantly, positively associated with state median income $(r=.142, p<.01)$, state percentage of Asian residents $(r=.147, p<.000)$, state percentage of Native Hawaiian or Pacific Islander residents $(r=.150, p<.000)$, state percentage of residents of two or more races $(r=.150, p<.000)$, and negatively associated with state percentage of American Indian or Alaska Native residents $(r=-.133$, $p<.01)$, state percentage of White residents $(r=-.117, p<.01)$, and state percentage of residents of some other race $(r=-.131, p<.01)$. In our bivariate analysis, asset limits were unrelated to the percentage of Black residents, unemployment rate, maximum monthly benefit, the poverty rate, or the political makeup of either houses. See Table 3 for all bivariate relationships.

Table 2. Descriptive Statistics

\begin{tabular}{lrrrrr}
\hline Variable & $n$ & Minimum & Maximum & \multicolumn{1}{c}{ Mean } & $S D$ \\
\hline Unemployment rate & 867 & 2.300 & 13.800 & 5.776 & 2.003 \\
Poverty rate & 867 & 4.500 & 25.800 & 12.684 & 3.475 \\
State median income & 561 & $32,938.000$ & $75,847.000$ & $51,221.955$ & 8848.725 \\
Max monthly Temporary Assistance for Needy & 867 & 164.000 & 923.000 & 425.269 & 161.512 \\
$\quad$ Families benefit & & & & & \\
\% Democratic State House & 833 & 0.130 & 0.920 & 0.508 & 0.162 \\
\% Democratic State Senate & 833 & 0.110 & 0.960 & 0.498 & 0.174 \\
Black & 561 & 0.003 & 0.568 & 0.111 & 0.110 \\
American Indian/Alaska Nat & 561 & 0.001 & 0.146 & 0.016 & 0.028 \\
Asian & 561 & 0.004 & 0.420 & 0.037 & 0.055 \\
Native Hawaiian/Pacific Islander & 561 & 0.000 & 0.104 & 0.003 & 0.013 \\
Some other race & 561 & 0.002 & 0.173 & 0.032 & 0.031 \\
Two or more Races & 561 & 0.007 & 0.245 & 0.029 & 0.031 \\
White & 561 & 0.246 & 0.966 & 0.773 & 0.137 \\
\hline
\end{tabular}


Table 3. Correlation: Relationship between Temporary Assistance for Needy Families (TANF) Asset Limits and StateLevel Economic, Demographic, and Racial Characteristics

\begin{tabular}{lc}
\hline Variable & TANF Asset Limits \\
\hline Maximum TANF benefit & -.012 \\
Unemployment rate & .053 \\
State median income & $.142^{* *}$ \\
Poverty rate & -.008 \\
\% Democratic State House & .004 \\
$\%$ Democratic State Senate & .047 \\
$\%$ Black residents & .082 \\
$\%$ White residents & $-.117^{* *}$ \\
$\%$ Asian residents & $.147^{* * *}$ \\
$\%$ Native Hawaiian/Pacific Islander & $.150^{* * *}$ \\
$\%$ American Indian and Alaska Native & $-.133^{* *}$ \\
$\%$ Two or more races & $.150^{* * *}$ \\
$\%$ Some other race & $-.131^{* *}$ \\
\hline
\end{tabular}

${ }^{*} p<.05,{ }^{* *} p<.01,{ }^{* * *} p<.001$.

\section{Multiple regression}

A multiple regression was employed to explore the predictive nature of the independent variable regressors on the dependent test variable. One standard multiple regression was conducted to address whether poverty rate, unemployment rate, maximum monthly TANF benefit, percentage of state upper and lower house that is Democratic, median income, or state race distribution are predictive of TANF asset limits. The standard multiple regression for the correlates of statelevel economic, demographic, race, and TANF asset limits were statistically significant (see Table 4). The multiple regression analysis revealed that the 12 variable model significantly contributed to the variance of TANF asset limits, $F$ $(12,526)=6.405, p<.000$, and accounted for $12.8 \%$ of the variance. TANF asset limits appear to have a different set of predictive factors in comparison to the

Table 4. Multiple Regressions: Effects of State-Level Economic, Demographic, and Racial Predictors on Temporary Assistance for Needy Families (TANF) Asset Limit

\begin{tabular}{lccc}
\hline & \multicolumn{3}{c}{ TANF Asset Limits $^{\mathrm{a}}$} \\
\cline { 2 - 4 } Variable & $b$ & SE $b$ & $\beta$ \\
\hline Unemployment rate & .001 & .069 & .001 \\
Poverty rate & .034 & .057 & .040 \\
State median income & $8.095 \mathrm{E}-5$ & .000 & $.237^{* *}$ \\
Max monthly TANF & -.002 & .001 & -.085 \\
\% Democratic State House & -4.516 & 1.783 & -.246 \\
\% Democratic State Senate & 4.264 & 1.527 & $.256^{* *}$ \\
Black & 3.798 & 1.849 & $.120^{*}$ \\
American Indian and Alaska Native & -20.034 & 7.291 & $-.186^{* *}$ \\
Native Hawaiian/Pacific Islander & -24.922 & 41.824 & -.109 \\
Asian & -10.512 & 10.161 & -.195 \\
Some other race & -9.928 & 5.771 & -.104 \\
Two or more races & 39.915 & 16.145 & $.421^{*}$ \\
\hline
\end{tabular}

Notes. ${ }^{\mathrm{a}} F(12,526)=6.405, p<.001 ;$ Adjusted $R^{2}=.108$.

${ }^{*} p<.05,{ }^{* *} p<.01,{ }^{* *} p<.001$. 
income threshold described in previous research (Brown \& Best, 2017). Individually six of the 12 variables significantly predicted TANF asset limits.

In our regression, asset limits were significantly, positively associated with State median income $(t=3.267, p<.01)$, percentage of State Senate that is Democratic $(t=2.793, p<.01)$, state percentage of Black residents $(t=2.054$, $p<.05)$, state percentage of residents of two or more races $(t=2.472$, $p<.05)$, and significantly, negatively associated with, state percentage of American Indian or Alaska Native residents $(t=-2.748, p<.01)$. Unemployment rate, poverty rate, maximum monthly TANF benefits for family of three, percentage of State House that is Democratic, Native Hawaiian/Pacific Islander, Asian, and some other race were not significantly related to TANF asset limits, after controlling for all variables in the model.

\section{Implications}

Although limited in scope, this research makes important contributions to the larger field of welfare politics. Although one might assume that generous asset limits would be associated with relatively generous benefit levels, that was not the case in the current analysis, leading us to believe that asset-limit determination may follow separate logic than that used to determine maximum monthly benefits. Indeed, unlike Brown and Best (2017) analysis of TANF income limits, TANF asset limits do appear to be influenced by state economy (at least in terms of state median income) and the presence of a Democratic State Senate.

Our finding that asset limits were positively associated with the percentage of Black and multiracial residents is in contrast to previous research (Brown \& Best, 2017; Soss et al., 2008). Because so few states have eliminated or significantly increased their limits, there appears to be differences in the process of asset-test determination than other welfare policies. This is potentially good news for advocates who seek to expand asset development opportunities to low-income families. With eight states eliminating asset tests altogether and a further 30 excluding IDAs, there are improved opportunities for low-income families to build assets and gain long-term financial stability. However, IDAs may only be used for home ownership, education, and small business development and therefore provide little cushion to families experiencing financial shocks such as an emergency medical bill or car repair. Only $37 \%$ of Americans report having enough cash reserves to handle a $\$ 500$ financial emergency (McGrath, 2016).

As with any study, there are limitations that need to be considered. The multivariate analysis revealed several predictive factors regarding TANF asset limits; however, the model only explained $12.8 \%$ of the variance, which means there is more to explore when explaining TANF asset limits. It is possible that the process has been idiosyncratic and would greatly benefit 
from further research. We suspect that the influence of advocacy organizations (Prosperity Now, 2018) that have been quietly working to remove barriers to asset accumulation among the poor have influenced this policy variance.

\section{Disclosure statement}

No potential conflict of interest was reported by the authors.

\section{ORCID}

Leah Hamilton (D) http://orcid.org/0000-0002-1253-171X

Peter R. Fawson (D) http://orcid.org/0000-0001-7037-9392

\section{References}

Amenta, E., Bonastia, C., \& Caren, N. (2001). US social policy in comparative and historical perspective: Concepts, images, arguments, and research strategies. Annual Review of Sociology, 27(1), 213-234. doi:10.1146/annurev.soc.27.1.213

Bansak, C., Mattson, H., \& Rice, L. (2010). Cars, employment, and single mothers: The effect of welfare asset restrictions. Industrial Relations: A Journal of Economy and Society, 49(3), 321-345. doi:10.1111/j.1468-232X.2010.00603.x

Bent-Goodley, T. B., Sherraden, M. S., Frey, J. J., Birkenmaier, J., Callahan, C., \& McClendon, G. G. (2016). Celebrating six decades of social work and advancing financial capability and asset development. Social Work, 61(4), 293-295. doi:10.1093/sw/sww058

Brown, H. E., \& Best, R. K. (2017). Logics of redistribution. Sociological Perspectives, 60(4), 786-809. doi:10.1177/0731121416656843

Brown-Robertson, L., \& Otabor, C. (2015). The cost of asset testing for the CalWORKs program. Howard University. Retrieved from http://citeseerx.ist.psu.edu/viewdoc/down load?doi=10.1.1.705.8951\&rep=rep1\&type $=$ pdf

Bureau of Labor Statistics. (2018). Employment status of the civilian noninstitutional population, 1943 to date. Washington, D.C.: United States Department of Labor. Retrieved from http://www.bls.gov/cps/cpsaat01.pdf

Fletcher, C. N., Garasky, S. B., Jensen, H. H., \& Nielsen, R. B. (2010). Transportation access: A key employment barrier for rural low-income families. Journal of Poverty, 14(2), 123-144. doi:10.1080/10875541003711581

Gehr, J. (2016). Eliminating asset limits: Creating savings for families and state governments. Washington, D.C.: Center for Law and Social Policy. Retrieved from https://www.clasp. org/sites/default/files/public/resources-and-publications/publication-1/ Eliminating-AssetLimits-Creating-Savings-for-Families-and-State-Governments.pdf

Hamilton, L., Alexander-Eitzman, B., \& Royal, W. (2015). Shelter from the storm: TANF, assets and the great recession. SAGE Open, 5(1), 1-6. doi:10.1177/2158244015572487

Hurst, E., \& Ziliak, J. P. (2006). Do welfare asset limits affect household saving? The Journal of Human Resources, 41(1), 46-71. doi:10.3368/jhr.XLI.1.46

McDonald, G., Orszag, P., \& Russell, G. (2005). The effect of asset tests on saving. Washington, D.C.: Center on Budget Policies and Priorities. Retrieved from http://www.cbpp.org/files/6-21-05soc sec-meth.pdf 
McGrath, M. (2016, January 6). 63\% of Americans don't have enough savings to cover A $\$ 500$ emergency. Retrieved from https://www.forbes.com/sites/maggiemcgrath/2016/01/06/63-of -americans-dont-have-enough-savings-to-cover-a-500-emergency/

Nam, Y. (2008). Welfare reform and asset accumulation: Asset limit changes, financial assets, and vehicle ownership. Social Science Quarterly, 89(1), 133-154. doi:10.1111/ssqu.2008.89.issue-1

Ong, P. M. (2002). Car ownership and welfare-to-work. Journal of Policy Analysis and Management, 21(2), 239-252. doi:10.1002/(ISSN)1520-6688

Pew Charitable Trusts. (2016, July 7). Do limits on family assets affect participation in, costs of TANF? Retrieved from http://pew.org/29n0ICJ

Piven, F. F., \& Cloward, R. (1993). Regulating the poor: The functions of public welfare (Updated, subsequent edition). New York, NY, USA: Vintage.

Powers, E. T. (1998). Does means-testing welfare discourage saving? Evidence from a change in AFDC policy in the United States. Journal of Public Economics, 68(1), 33-53. doi:10.1016/S0047-2727(97)00087-X

Prosperity Now. (2018, May 18). Asset limits in public benefit programs. Retrieved from https://scorecard.prosperitynow.org/data-by-issue

Personal Responsibility and Work Opportunity Reconciliation Act, 42 USC $\$ 601$ (1996).

Rand, D. (2007). Reforming state rules on asset limits: How to remove barriers to saving and asset accumulation in public benefit programs. Clearinghouse REVIEW Journal of Poverty Law and Policy, (March-April), 625-636.

Schram, S. F., \& Soss, J. (2001). Success stories: Welfare reform, policy discourse, and the politics of research. The Annals of the American Academy of Political and Social Science, 577, 49-65. doi:10.1177/000271620157700105

Soss, J., Fording, R. C., \& Schram, S. F. (2008). The color of devolution: Race, federalism, and the politics of social control. American Journal of Political Science, 52(3), 536-553. doi:10.1111/ajps.2008.52.issue-3

Sullivan, J. (2006). Welfare reform, saving, and vehicle ownership: Do asset limits and vehicle exemptions matter?Journal of Human Resources, 41(1), 73-105.

University of Kentucky Center for Poverty Research. (2017, June 18). UKCPR national welfare data, 1980-2015. Retrieved from http://www.ukcpr.org/data

Urban Institute. (2018, June 27). The welfare rules database. Retrieved from https://wrd. urban.org/wrd/Query/query.cfm

US Census Bureau. (2018a). Data. Retrieved from https://www.census.gov/data.html

US Census Bureau. (2018b). American community survey data. Retrieved from https://www. census.gov/programs-surveys/acs/data.html 